http://dx.doi.org/10.6113/TKPE.2012.17.4.368

\title{
$\mathrm{DC}$ Grid를 위한 새로운 구조의 DC Solid-State Circuit Breaker
}

\author{
김진영 ${ }^{1}$, 김인동 $^{\dagger}$, 노의철 $^{2}$
}

\section{A Novel DC Solid-State Circuit Breaker for DC Grid}

\author{
Jin-Young $\mathrm{Kim}^{1}$, In-Dong $\mathrm{Kim}^{\dagger}$, and Eui-Cheol $\mathrm{Nho}^{2}$
}

\begin{abstract}
According to developed distributed generators, Solid State Circuit Breaker(SSCB) is essential for high power quality of DC Grid. In this paper, a simple and new structure of DC SSCB with a fast circuit breaker and fault current limiter is proposed. It can help to choice low specification of elements because of the limiting of fault current and achieve economic efficiency for minimizing auxiliary SCRs. Also all of SCRs have little switching loss because they operate under ZVS and ZCS. Through simulations and experiments of short-circuit fault, the performance characteristic of proposed circuit is verified and a guideline is so suggested that the DC SSCB is applied for a different DC grid using formulas.
\end{abstract}

Keywords: DC circuit breaker, solid-state circuit breaker(SSCB), fault current limiting, thyristor

\section{1. 서 론}

최근 태양광 발전 및 풍력 발전 등 분산전원이 발달 함에 따라 일반 가정집에도 분산전원이 널리 보급되는 추세이다. 이로 인해 기존의 $\mathrm{AC}$ 전송에 비해서 전력효 율을 높일 수 있는 $\mathrm{DC}$ 전송이 주요 관심사가 되고 있 다. ${ }^{[1]}$ 게다가 IT기술의 발달에 따른 민감한 부하들이 대 중적으로 보급되어 있어 단락사고나 전압 새그 및 스웰 등에 민감하게 반응하므로 안정적으로 전력을 공급하는 기술이 요구된다. ${ }^{[2]}$ 특히 분산전원들은 낙뢰, 강풍, 폭설 등의 자연현상에 민감하므로 사고 발생 시 신속하게 계 통으로부터 분리할 수 있는 성능이 필요하다. 하지만 $\mathrm{AC}$ 전송에 비해 $\mathrm{DC}$ 전송은 안정성에 관한 기술이 부 족한 실정이다. 게다가 전류의 영교차점을 갖는 $\mathrm{AC}$ 그 리드에 비해 $\mathrm{DC}$ 그리드는 전류의 영교차점이 없으므로 과전류와 단락전류를 차단하기 어렵다는 단점이 있다. ${ }^{[3]}$ 또한 단락사고로 인한 아크나 스파크에 의한 전기화재 가 발생하므로 사고 전류를 신속하게 차단하지 못 한다 면 더 큰 피해가 발생하게 된다. ${ }^{[4]}$ 사고 계통을 신속하

Paper number: TKPE-2012-17-4-12 ISSN: 1229-2214

† Corresponding author: idkim@pknu.ac.kr, Dept. of Electrical Eng., Pukyong National University

Tel: +82-51-629-6318 Fax: +82-51-629-6305

12 Dept. of Electrical Eng., Pukyong National University

Manuscript received May 21, 2012; accepted Jun. 18, 2011
게 분리하는 기술로는 기계식 차단기와 반도체 차단기 (Solid-State Circuit Breaker: SSCB)가 많이 사용된다. 기계식 차단기는 물리적 구조로 인하여 수십 $[\mathrm{ms}]$ 이후 에 차단이 가능하므로 신속한 차단이 불가능하여 피해 방지가 어렵다. ${ }^{[5]}$ 이에 비해 $\mathrm{SSCB}$ 는 $4[\mathrm{~ms}]$ 이내로 차 단이 가능하여 사고최대전류 보다 매우 낮은 전류에서 차단되므로 사고의 피해를 줄일 수 있다. $\mathrm{SSCB}$ 에 사용 되는 반도체 스위칭 소자에는 여러 가지가 있으나 $\mathrm{SCR}$ 을 사용하는 것이 경제적이며 도통 손실이 매우 작 다. ${ }^{[6-7]}$ 하지만 $\mathrm{SCR}$ 을 이용한 $\mathrm{SSCB}$ 들은 대부분 전원전 류(Line commutation)가 가능한 $\mathrm{AC}$ 그리드에 기반을 두고 제안되었기 때문에 $\mathrm{DC}$ 그리드에 그대로 적용하기 가 어렵다. 따라서 $\mathrm{DC}$ 그리드에는 $\mathrm{AC} \mathrm{SSCB}$ 와는 다른 구조를 갖는 $\mathrm{DC} \mathrm{SSCB}$ 에 관한 연구가 필요하다.

$\mathrm{DC} \mathrm{SSCB}$ 가 갖추어야 할 성능으로는 전압의 새그/스 웰을 판별하여 차단하는 기술과 과전류를 판별하여 차 단하는 기술 등 여러 가지가 있다. 하지만 그 중에 단락 사고를 판별하여 차단하는 기술이 가장 중요하다. $\mathrm{DC}$ 그리드에 단락사고가 발생하면 사고 전류는 낮은 임피 던스로 인해 급격하게 증가하게 되고 전류의 영교차점 이 없으므로 신속한 차단이 되지 않는다면 매우 큰 피 해가 발생하게 된다. 따라서 $\mathrm{DC} \mathrm{SSCB}$ 에는 급격하게 증 가하는 사고전류를 억제할 수 있는 제한 기능과 사고 전류를 $4[\mathrm{~ms}]$ 이내에 신속하게 차단할 수 있는 차단 기능의 확보가 중요하다. 


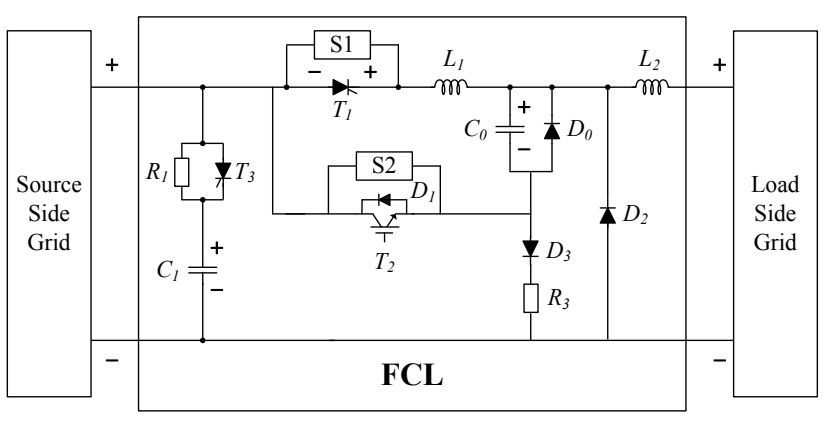

Fig. 1 Previous Solid-State Fault Current Limiter



Fig. 2 Previous DC Solid-State Circuit Breaker

그림 1 은 단락 전류의 제한 기능을 중점으로 둔 기존 에 제시된 $\mathrm{FCL}$ (Fault current limiter)의 회로이다. ${ }^{[8]}$ $\mathrm{FCL}$ 은 에너지를 부하 측에 공급하기 위하여 도통 손실 이 작은 $\mathrm{SCR}\left(\mathrm{T}_{1}\right)$ 을 주 스위치로 사용하고 사고 전류를 제어하기 위하여 $\operatorname{IGBT}\left(\mathrm{T}_{2}\right)$ 를 보조 스위치로 사용한다. 부하 측에 단락 사고가 발생하면 $\operatorname{IGBT}\left(\mathrm{T}_{2}\right)$ 가 턴온 되 어 $\mathrm{C}_{0}$ 에 저장된 양의 전압에 의해 $\mathrm{SCR}\left(\mathrm{T}_{1}\right)$ 은 자연 턴오 프가 되고 $\mathrm{FCL}$ 은 $\mathrm{IGBT}\left(\mathrm{T}_{2}\right)$ 의 온/오프 동작을 통해 벅 컨버터로 동작하게 된다. $\mathrm{IGBT}\left(\mathrm{T}_{2}\right)$ 가 쵸퍼 동작을 하므 로 $\mathrm{FCL}$ 은 단락 전류를 임의의 크기로 제어하게 되며 일정 시간 동안 기준 전류의 크기로 감소하지 않으면 $\mathrm{IGBT}\left(\mathrm{T}_{2}\right)$ 를 완전히 오프하여 사고 전류를 차단하게 된 다. 따라서 FCL은 급격하게 증가하는 단락 전류를 임의 의 크기로 제어하다가 완전히 차단하므로 사고 피해를 줄일 수 있게 된다. 하지만 $\mathrm{IGBT}\left(\mathrm{T}_{2}\right)$ 는 부하 전류에 비 해 크기가 큰 사고 전류를 하드 스위칭 하므로 열과 함 께 큰 손실을 갖게 된다. 따라서 $\mathrm{FCL}$ 은 급격하게 증가 하는 단락 전류를 제어 할 수 있는 장점이 있으나 사고 전류를 IGBT를 통해 강제로 차단하므로 SCR에 비해서 큰 용량의 IGBT가 요구되며 방열을 위한 추가적인 요 소가 필요하므로 경제적이지 못하다.

그림 2 는 사고 전류의 신속한 차단을 목적으로 기존 에 제시된 $\mathrm{DC} \mathrm{SSCB}$ 이다. ${ }^{[9]}$ 그림 2 의 회로는 주 스위치 로 $\operatorname{SCR}\left(\mathrm{T}_{11}\right)$ 을 사용하여 부하 측에 에너지를 공급하고 사고 전류를 차단하기 위해 $\mathrm{L}-\mathrm{C}$ 공진 전류를 이용한다.

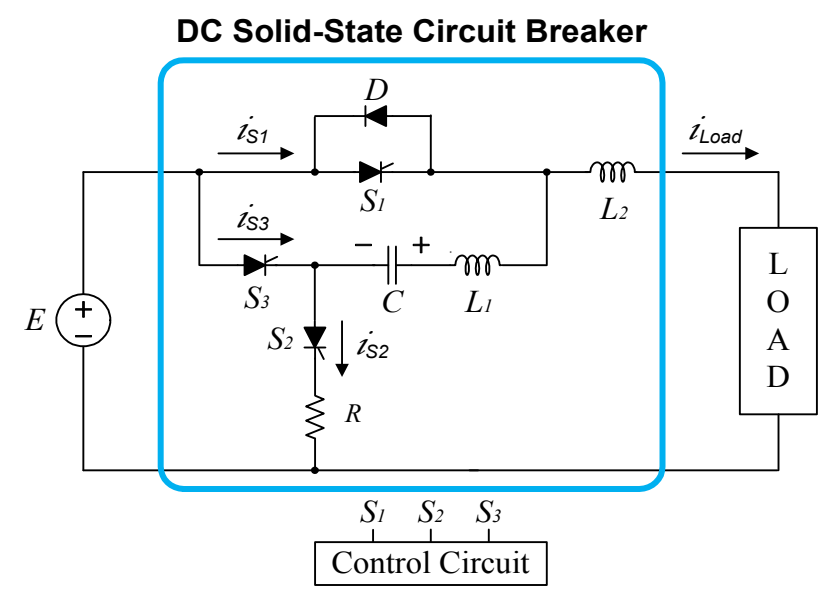

Fig. 3 Proposed DC Solid-State Circuit Breaker

사고가 발생하면 보조 스위치 $\left(\mathrm{T}_{25}, \mathrm{~T}_{22}\right)$ 는 턴온 되어 사 고 전류보다 크기가 큰 $\mathrm{L}-\mathrm{C}$ 공진 전류 $\left(\mathrm{T}_{25}-\mathrm{C}_{1}-\mathrm{L}_{1}-\mathrm{T}_{22}\right)$ 가 흐르게 되어 주 스위치 $\mathrm{SCR}\left(\mathrm{T}_{11}\right)$ 를 신속하게 턴오프 시킨다. 주 스위치 $\left(\mathrm{T}_{11}\right)$ 와 보조 스위치 $\left(\mathrm{T}_{21} \sim \mathrm{T}_{25}\right)$ 는 모두 $\mathrm{SCR}$ 로 구성되어 손실이 작다. 하지만 그림 2 의 회로는 사고 전류를 제한하는 기능이 없으므로 과전류 차단은 용이하지만 단락 전류의 차단이 어렵다는 단점이 있다. 급격하게 증가하는 단락 전류를 차단하기 위해서는 단락 전류 보다 큰 $\mathrm{L}-\mathrm{C}$ 공진 전류를 얻어야 하므로 매우 큰 용량의 커패시터가 요구 된다. 또한 $\mathrm{L}-\mathrm{C}$ 공진 전류를 얻기 위해서는 그림 2 의 $\mathrm{B}$ 처럼 커패시터의 충전 패스 $\left(\mathrm{T}_{21}, \mathrm{~T}_{24}\right)$ 와 방전 패스 $\left(\mathrm{T}_{25}, \mathrm{~T}_{22}\right)$ 를 구성해야 하므로 많은 보조 $\mathrm{SCR}$ 을 사용하게 되어 경제성이 떨어지게 된다.

이러한 배경으로 본 연구에서는 신속한 차단이 가능 하며 사고 전류를 제한 할 수 있는 기능을 갖는 간단한 구조의 새로운 $\mathrm{DC} \mathrm{SSCB}$ 를 제안 한다. 제안하는 $\mathrm{DC}$ $\mathrm{SSCB}$ 는 가정용 $\mathrm{DC}$ 전송으로 적합한 $380[\mathrm{~V}], 5[\mathrm{~kW}]$ 급으로 설계하여 시뮬레이션과 실험을 통해 동작특성을 검증한다. 또한 다른 용량의 $\mathrm{DC}$ 그리드에 적용이 가능 하도록 설계방향을 제시하여 응용이 가능하도록 한다.

\section{2. 제안하는 DC Solid-State Circuit Breaker}

그림 3은 본 연구에서 제안하는 $\mathrm{DC} \mathrm{SSCB}$ 회로이다. $\mathrm{SSCB}$ 의 정상 운전 시에는 $\mathrm{SCR}\left(\mathrm{S}_{1}\right)$ 과 $\mathrm{L}_{2}$ 를 통해 에너지 가 전달되고 사고가 발생하면 $\mathrm{L}_{1}-\mathrm{C}$ 공진 전류 $\mathrm{i}_{\mathrm{S} 3}\left(\mathrm{~S}_{3}-\mathrm{C}-\mathrm{L}_{1}\right)$ 에 의해 신속하게 차단이 된다. 정상 운전 시의 $\mathrm{L}_{2}$ 는 임피던스가 없는 선로로 동작하므로 부하 측 에 아무런 영향을 주지 않는다. 하지만 단락 사고가 발 생하여 전류가 증가하게 되면 $\mathrm{L}_{2}$ 는 인덕터로 동작하여 단락 전류의 급격한 증가를 제한하게 된다. 따라서 $\mathrm{L}_{2}$ 에 의해 단락 전류가 제한되므로 사고 전류의 차단에 요구 되는 $\mathrm{L}_{1}-\mathrm{C}$ 공진 전류의 크기가 작아지고 $\mathrm{SCR}$ 의 용량도 낮아지므로 제안한 $\mathrm{DC} \mathrm{SSCB}$ 는 낮은 사양의 설계가 가 능하여 경제성이 높다. 또한 사고 전류를 차단하기 위해 
사용되는 보조 스위치 $\left(\mathrm{S}_{2}, \mathrm{~S}_{3}\right)$ 는 2개 이므로 기존의 $\mathrm{DC}$ $\mathrm{SSCB}$ 에 비해 구조가 간단하며 모든 $\mathrm{SCR}$ 은 턴온과 턴 오프 시 $\mathrm{L}_{1}-\mathrm{C}$ 공진전류를 이용한 ZVS, ZCS 동작을 하 므로 스위칭 손실이 작다.

그림 4 는 제안하는 $\mathrm{DC} \mathrm{SSCB}$ 의 모드에 따른 동작 파 형을 나타낸다. 그림 4에서 보이는 바와 같이 제안하는 $\mathrm{DC} \mathrm{SSCB}$ 는 커패시터를 충전하는 충전 모드 $\left(\mathrm{t}_{1} \sim \mathrm{t}_{2}\right)$, 부 하에 에너지를 공급하는 정상 모드 $\left(\mathrm{t}_{2} \sim \mathrm{t}_{3}\right)$, 사고 전류를 차단하는 차단 모드 $\left(t_{3} \sim t_{7}\right)$ 로 나누어진다. 충전 모드에서 $\mathrm{S}_{2}$ 의 턴온은 $\mathrm{S}_{1}$ 에 비해 $\mathrm{t}_{1} \sim \mathrm{t}_{1}{ }^{\prime}$ 만큼의 시간 지연을 가지 나 충전모드의 동작 특성을 살펴보기 위함이므로 $\mathrm{S}_{1}$ 과 $\mathrm{S}_{2}$ 는 동시에 턴온 되어도 문제가 발생하지 않는다. $\mathrm{t}_{3}$ 에 서 단락 사고가 발생하면 차단모드는 시작되고 사고 전 류가 전부하 전류의 3 4배를 초과하는 $\mathrm{t}_{4}$ 가 되면 단락 사고로 판별되어 $\mathrm{S}_{3}$ 는 턴온된다. 그림 5 는 제안한 $\mathrm{SSCB}$ 의 각 모드를 나타내며 시간에 따른 동작 특성은 다음 과 같다.

(a) 모드 1 (충전 모드 : $\mathrm{t}_{1} \sim \mathrm{t}_{1}^{\prime} \sim \mathrm{t}_{2}$ )

제안한 $\mathrm{DC} \mathrm{SSCB}$ 는 $\mathrm{L}_{1}-\mathrm{C}$ 공진 전류를 이용하여 사 고 전류를 차단하므로 사전에 커패시터를 충전하여야 한다. 따라서 모드 1 에서는 $\mathrm{S}_{1}$ 과 $\mathrm{S}_{2}$ 가 턴온 되어 커패시 터를 충전하게 된다. 충전 전류 $\mathrm{i}_{\mathrm{S} 2}$ 가 흐르는 충전 루프 의 전압방정식은 식 (1)과 같다.

$$
E=L_{1} \frac{d i_{S 2}}{d t}+\frac{1}{C} \int i_{S 2} d t+R i_{S 2}
$$

$\mathrm{S}_{1}$ 은 시간 $\mathrm{t}_{1}$ 에서 $\mathrm{L}_{2}$ 에 의해 ZCS 턴온 동작을 하고 $\mathrm{S}_{2}$ 는 시간 $\mathrm{t}_{1}{ }^{\prime}$ 에서 $\mathrm{L}_{1}-\mathrm{C}$ 에 의해 $\mathrm{ZCS}$ 턴온 동작을 하게 되므로 스위칭 손실이 발생하지 않는다. 커패시터의 충 전이 완료되면 $\mathrm{S}_{2}$ 는 $\mathrm{ZCS}$ 턴오프 동작을 하며 자연 턴오 프가 되고 $\mathrm{DC} \mathrm{SSCB}$ 의 정상 모드가 시작된다.

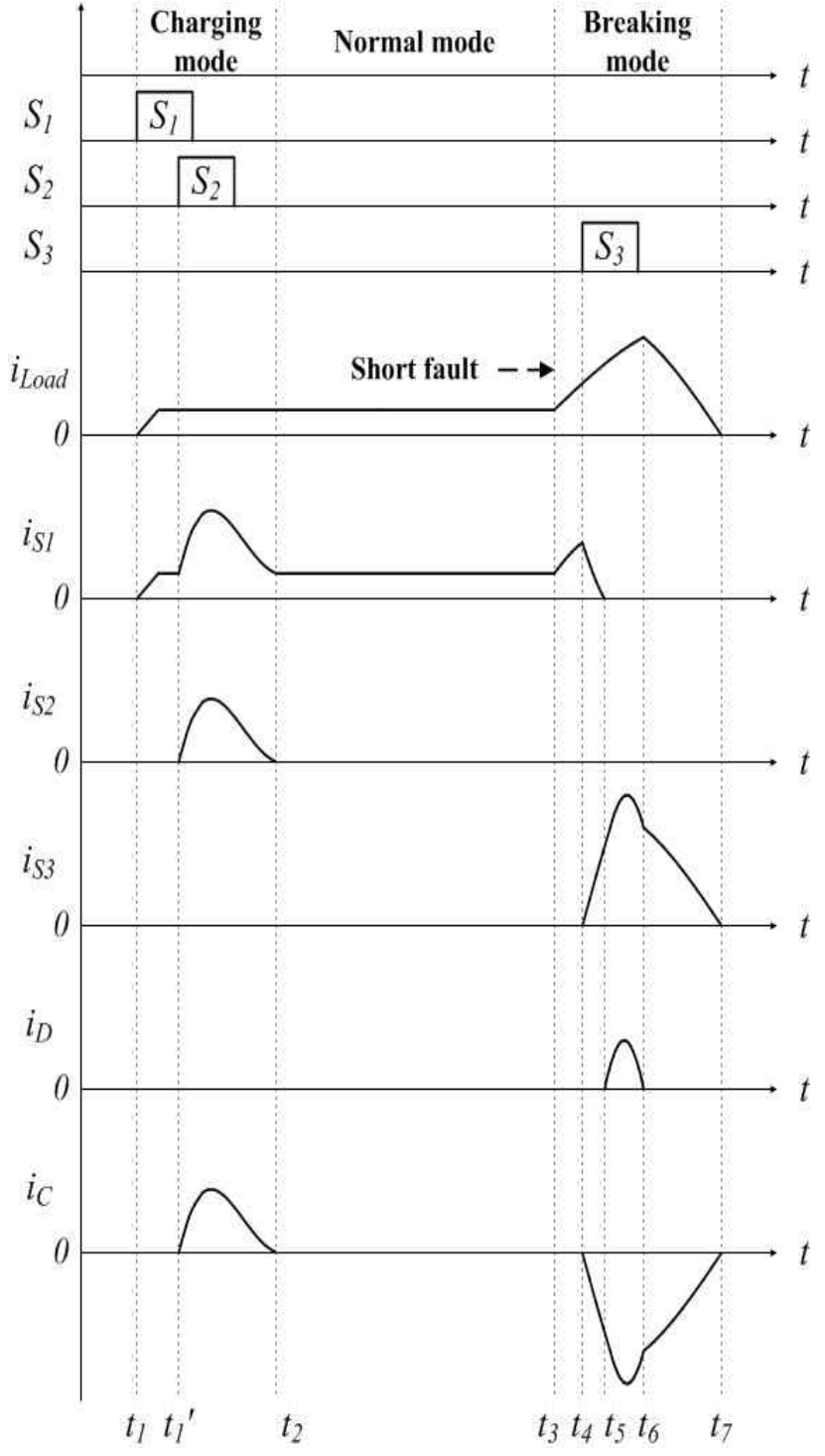

Fig. 4 Operating waveforms of the proposed DC SSCB

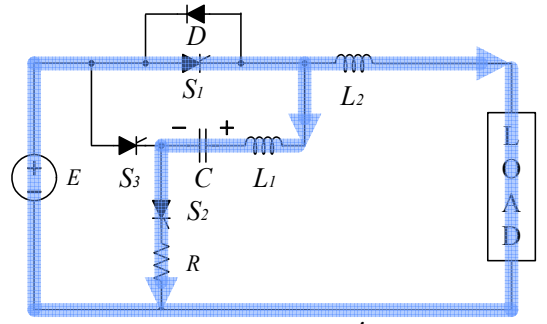

(a) Mode $1\left(t 1 \sim t 1^{\prime} \sim t 2\right)$



(d) Mode $4(t 4 \sim t 5)$

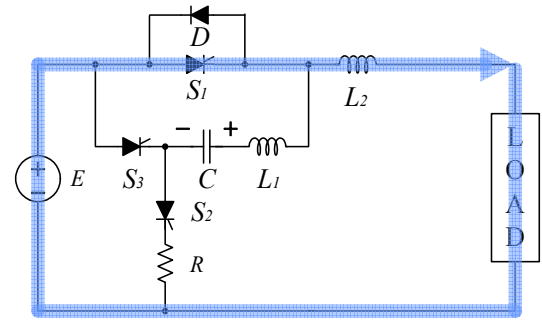

(b) Mode $2(t 2 \sim t 3)$



(e) Mode $5(t 5 \sim t 6)$

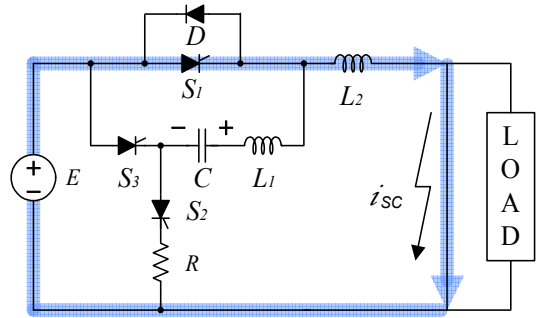

(c) Mode $3(t 3 \sim t 4)$

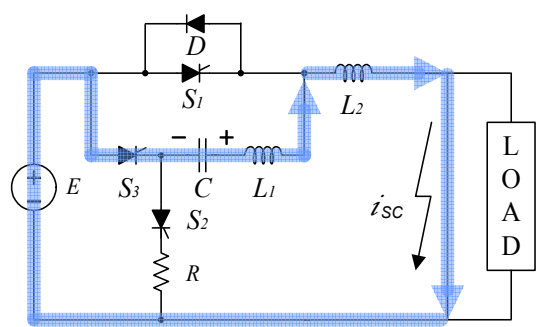

(f) Mode $6(t 6 \sim t 7)$

Fig. 5 Operating modes of the proposed DC SSCB 
(b) 모드 2 (정상 모드 : $\mathrm{t}_{2} \sim \mathrm{t}_{3}$ )

모드 2 는 $\mathrm{DC}$ 그리드의 정상 운전 모드로써 $\mathrm{S}_{1}$ 을 통 해 부하에 에너지를 전달하게 된다. $\mathrm{L}_{2}$ 는 임피던스가 없 는 보통의 전송선로처럼 동작하므로 $\mathrm{DC}$ 그리드에 영향 을 주지 않는다.

(c) 모드 3 (차단 모드 : $\mathrm{t}_{3} \sim \mathrm{t}_{4}$ )

$\mathrm{SSCB}$ 가 정상 모드로 동작하다가 시간 $\mathrm{t}_{3}$ 에서 부하 측 에 단락 사고가 발생하게 되면 $\mathrm{SSCB}$ 의 차단 모드가 시 작된다. $\mathrm{DC}$ 그리드에서 단락 회로가 되면 일반적으로 단락 전류 isc는 급격하게 증가하지만 제안하는 $\mathrm{DC}$ $\mathrm{SSCB}$ 를 사용할 시는 인덕터로 동작하는 $\mathrm{L}_{2}$ 에 의해 단 락전류가 억제되게 된다. 단락 회로의 전압과 전류 방정 식은 다음과 같다.

$$
\begin{aligned}
& E=L_{2} \frac{d i_{S C}}{d t} \\
& i_{S C}=i_{S 1}=\frac{E}{L_{2}}\left(t-t_{3}\right)+i_{L O A D}
\end{aligned}
$$

식 (3)을 통해 알 수 있듯이 단락전류 $\mathrm{isc}_{\mathrm{SC}}$ 는 $\mathrm{L}_{2}$ 에 의해 제어가 된다. 모드 3 에서는 단락전류 $\mathrm{i}_{\mathrm{SC}}$ 의 크기가 사고 로 판단되는 전류보다 작으므로 $\mathrm{S}_{3}$ 는 동작하지 않는다.

(d) 모드 4 (차단 모드 : $t_{4} \sim t_{5}$ )

단락 전류 $\mathrm{isc}_{\mathrm{SC}}$ 감차 증가하여 사고로 판별되는 시간 $\mathrm{t}_{4}$ 가 되면 $\mathrm{S}_{3}$ 는 턴온 되어 $\mathrm{L}_{1}-\mathrm{C}$ 공진 전류 $\mathrm{i}_{\mathrm{S} 3}$ 가 흐르게 된다. $\mathrm{S}_{1}$ 은 온 상태이며 $\mathrm{S}_{3}-\mathrm{C}-\mathrm{L}_{1}$ 루프의 저항은 거의 0 $[\Omega]$ 이므로 전압방정식은 식 (4)와 같다.

$$
V_{S 1}=V_{C}+V_{L 1}=0
$$

따라서 $\mathrm{L}_{1}-\mathrm{C}$ 공진전류 $\mathrm{i}_{\$} 3$ 는 식 (5)와 같다.

$$
i_{S 3}=\frac{E}{\sqrt{\frac{L_{1}}{C}}} \sin \left(\frac{t-t_{4}}{\sqrt{L_{1} C}}\right) \quad\left(t_{4} \leq t \leq t_{6}\right)
$$

$\mathrm{S}_{1}$ 이 턴오프 되기 위해서는 $\mathrm{L}_{1}-\mathrm{C}$ 공진 전류 $\mathrm{i}_{\mathrm{S} 3}$ 가 단 락 전류 isc보다 커야 한다. 따라서 $\mathrm{L}_{1}-\mathrm{C}$ 공진 전류 is3 의 단위 증가량은 단락전류 $\mathrm{isc}_{\mathrm{SC}}$ 안위 증가량에 비해 매우 크기 때문에 $\mathrm{i}_{\mathrm{S} 1}$ 의 전류는 식 (6)에 따라서 점차 감 소하게 된다.

$$
i_{S 1}=i_{S C}-i_{S 3}
$$

$\mathrm{L}_{1}-\mathrm{C}$ 공진전류 $\mathrm{i}_{\mathrm{S} 3}$ 가 점차 증가하여 단락 전류 $\mathrm{isc}_{\mathrm{SC}}$ 와 같아지는 시간 $\mathrm{t}_{5}$ 가 되면 $\mathrm{i}_{\mathrm{S} 1}$ 은 $0[\mathrm{~A}]$ 가 되므로 $\mathrm{S}_{1}$ 은 자
연 턴오프 된다. $\mathrm{S}_{1}$ 은 전압이 $0[\mathrm{~V}]$ 이므로 턴오프 시 스 위칭 손실이 발생 하지 않는다.

(e) 모드 5 (차단 모드 : $t_{5} \sim t_{6}$ )

$\mathrm{t}_{5}$ 가 되면 $\mathrm{L}_{1}-\mathrm{C}$ 공진전류 $\mathrm{is}_{3}$ 는 단락 전류 $\mathrm{isc}_{\mathrm{S}}$ 보다 커 지므로 다이오드를 통해 흐르게 된다. 따라서 $t_{5} \sim t_{6}$ 구간 에는 식 (7)의 전류가 다이오드에 흐르게 되고 $\mathrm{L}_{1}-\mathrm{C}$ 공 진전류 $\mathrm{i}_{\mathrm{S} 3}$ 와 단락전류 $\mathrm{i}_{\mathrm{SC}}$ 의 크기가 같아지는 $\mathrm{t}_{6}$ 이 되면 다이오드는 오프 된다.

$$
i_{D}=i_{S 3}-i_{S C}
$$

$\mathrm{S}_{1}$ 이 완전히 턴오프 되기 위해서는 $\mathrm{t}_{5} \sim \mathrm{t}_{6}$ 구간의 다 이오드 도통 시간이 $\mathrm{SCR} \mathrm{S}_{1}$ 의 $\mathrm{t}_{\mathrm{q}}$ (턴오프 시간)보다 길 어야 한다. 따라서 $\mathrm{L}_{1}-\mathrm{C}$ 공진전류 $\mathrm{i}_{\mathrm{S} 3}$ 는 단락전류 $\mathrm{i}_{\mathrm{SC}}$ 보 다 충분히 커야 한다. $\mathrm{L}_{1}-\mathrm{C}$ 공진전류 $\mathrm{is}_{3}$ 의 크기는 식 (5)를 이용하여 얻을 수 있으며 $\mathrm{L}_{1}-\mathrm{C}$ 공진 전류 $\mathrm{i}_{53}$ 의 최대값은 식 (8)과 같다. $\mathrm{t}^{\prime}$ 는 $\mathrm{L}_{1}-\mathrm{C}$ 공진 전류 $\mathrm{i}_{\mathrm{S} 3}$ 가 최대 값을 가질 때의 시간이다.

$$
i_{S 3_{\max }}=\frac{E}{\sqrt{\frac{L_{1}}{C}}} \sin \left(\frac{t^{\prime}-t_{4}}{\sqrt{L_{1} C}}\right) \quad\left(t^{\prime}=t_{4}+\frac{\pi \sqrt{L_{1} C}}{2}\right)
$$

(f) 모드 6 (차단 모드 : $\mathrm{t}_{6} \sim \mathrm{t}_{7}$ )

모드 6에서는 $\mathrm{L}_{1}-\mathrm{C}$ 공진 전류 $\mathrm{i}_{53}$ 가 점차 감소하여 $\mathrm{S}_{3}$ 는 자연 턴오프 되고 사고 전류는 완전히 차단이 된다. $\mathrm{t}_{6} \sim \mathrm{t}_{7}$ 구간에는 $\mathrm{S}_{1}$ 과 다이오드가 턴오프 상태이므로 $\mathrm{i}_{\mathrm{S}_{3}}$ 와 isc는 같은 전류가 흐르게 되어 $\mathrm{L}_{1}$ 과 $\mathrm{L}_{2}$ 의 합성 인덕터 에 의한 $\mathrm{L}-\mathrm{C}$ 공진 전류가 흐르게 된다. 따라서 모드 6 에서의 전압방정식은 식 (9)가 된다.

$$
E=\left(L_{1}+L_{2}\right) \frac{d i_{S 3}}{d t}+\frac{1}{C} \int i_{S 3}+V_{C}\left(t_{6}\right)
$$

커패시터의 초기값 $\mathrm{V}_{\mathrm{C}}\left(\mathrm{t}_{6}\right)$ 는 $\mathrm{t}^{\prime} \sim \mathrm{t}_{6}$ 구간에서 $\mathrm{L}_{1}-\mathrm{C}$ 공진 전류 $\mathrm{i}_{53}$ 에 의해 충전된 전압이므로 식 (5)로부터 얻을 수 있다. 또한 $\mathrm{t}_{6}$ 에서의 $\mathrm{L}-\mathrm{C}$ 공진 전류의 초기값 $\mathrm{i}_{33}\left(\mathrm{t}_{6}\right)$ 는 식 (3)을 이용하여 구할 수 있다. 모드 6에서 커패시 터의 초기 전압 $\mathrm{V}_{\mathrm{C}}\left(\mathrm{t}_{6}\right)$ 와 $\mathrm{L}-\mathrm{C}$ 공진 전류의 초기값 $\mathrm{i}_{\mathrm{S}_{3}}\left(\mathrm{t}_{6}\right)$ 는 다음과 같다.

$$
\begin{aligned}
& V_{C O}=-E \cdot \cos \left(\frac{180\left(t_{6}-t_{4}\right)}{\pi \sqrt{L_{1} C}}\right) \\
& i_{S 3}\left(t_{6}\right)=\frac{E}{L_{2}}\left(t_{6}-t_{3}\right)+i_{L O A D}
\end{aligned}
$$

따라서 모드 6 에서의 $\mathrm{L}-\mathrm{C}$ 공진전류 $\mathrm{is}_{\mathrm{S} 3}$ 와 단락전류 
isc는 식 (12)가 된다.

$$
\begin{aligned}
i_{S 3}= & i_{S 3}\left(t_{6}\right) \cdot \cos \left(\frac{t-t_{6}}{\sqrt{L_{1}+L_{2}}}\right) \quad\left(t>t_{6}\right) \\
& +\frac{E-V_{C}\left(t_{6}\right)}{\sqrt{\frac{L_{1}+L_{2}}{C}}} \cdot \sin \left(\frac{t-t_{6}}{\sqrt{\left(L_{1}+L_{2}\right) C}}\right)
\end{aligned}
$$

\section{DC Solid-State Cirecuit Breaker의 설계}

본 논문에서 제안한 $\mathrm{DC} \mathrm{SSCB}$ 의 파라미터는 표 1 과 같다.

A. 충전 모드 $\left(t_{1} \sim t_{1}^{\prime} \sim t_{2}\right)$

그림 6 은 충전모드의 등가회로이며 그림 7 은 충전 모 드의 $\mathrm{i}_{\mathrm{S} 1}$ 과 $\mathrm{i}_{\mathrm{S} 2}$ 의 파형이다. $\mathrm{t}_{1}{ }^{\prime} \sim \mathrm{t}_{2}$ 구간 동안 $\mathrm{S}_{1}$ 에 흐르는 전류의 증가는 충전 전류 $\mathrm{i}_{52}$ 에 의해 결정되므로 충전 전류 $\mathrm{i}_{52}$ 의 설계가 요구된다.

충전 루프의 전압방정식은 식 (1)과 같으므로 충전 전 류 $\mathrm{i}_{2}$ 의 크기와 충전 시간은 $\mathrm{L}_{1}, \mathrm{C}, \mathrm{R}$ 에 의해 결정된다. 하지만 $\mathrm{L}_{1}, \mathrm{C}, \mathrm{R}$ 소자를 선정하기 이전에 충전 전류 $\mathrm{i}_{2}$ 는 임계제동 제어가 되어야 한다는 것을 유념해야 한다. 충 전 전류 $\mathrm{i}_{\mathrm{S} 2}$ 가 과제동 제어가 된다면 충전 시간이 길어 지게 되며 $\mathrm{S}_{2}$ 가 자연 턴오프 되기까지 많은 시간이 소 요된다. 게다가 $\mathrm{S}_{2}$ 가 턴오프 되지 못한 상황에서 사고 발생으로 인한 차단모드가 시작되면 $\mathrm{L}_{1}-\mathrm{C}$ 공진 전류 $\mathrm{i}_{\mathrm{S} 3}$ 는 $\mathrm{S}_{1}$ 을 차단하지 못하고 $\mathrm{S}_{2}$ 를 통해 전류가 흐르게 된 다. 또한 충전 전류 $\mathrm{i}_{\mathrm{S} 2}$ 가 부족제동 제어가 된다면 커패 시터의 충전 전압이 입력전압에 비해 높아지게 되어 $\mathrm{L}_{1}-\mathrm{C}$ 공진 전류 $\mathrm{i}_{S 3}$ 의 크기가 커지게 되므로 더 큰 용량 의 소자를 요구하게 된다. 따라서 $\mathrm{L}_{1}, \mathrm{C}, \mathrm{R}$ 은 충전 전류 $\mathrm{i}_{\mathrm{S} 2}$ 가 임계제동 제어가 되도록 선정하는 것이 안정적이 며 $\mathrm{L}_{1}, \mathrm{C}$ 를 선정하게 되면 $\mathrm{R}$ 은 식 (13)에 의해 자연적으 로 선정이 된다.

$$
R=2 \sqrt{\frac{L_{1}}{C}}
$$

그리고 임계제동 제어가 될 때의 충전 전류 $\mathrm{i}_{\mathrm{S} 2}$ 는 식 (14)와 같다.

$$
i_{S 2}=\frac{E}{L_{1}} t e^{-\frac{R}{2 L_{1}} t}
$$

차단 모드에서의 $\mathrm{L}_{1}-\mathrm{C}$ 공진 전류 $\mathrm{is}_{3}$ 는 저항 $\mathrm{R}$ 이 없 으므로 충전 전류 $\mathrm{i}_{52}$ 보다 큰 전류가 흐르기 때문에 $\mathrm{L}_{1}$ 과 $\mathrm{C}$ 은 차단 모드에서 선정해야 한다. 그러므로 충전 모드에서는 충전 시간만 고려하면 된다.

그림 8 은 $\mathrm{L}_{1}$ 과 $\mathrm{C}$ 의 용량에 따른 충전 전류 $\mathrm{i}_{\mathrm{S} 2}$ 의 충전 시간을 나타낸다. 충전 모드와 차단 모드의 동작이 4 [ms] 이내에 모두 이루어져야 하므로 충전 시간이 2.5
Table 1 System parameter

\begin{tabular}{|c|r|}
\hline Power rating & $5[\mathrm{~kW}]$ \\
\hline Source voltage E & $380[\mathrm{~V}]$ \\
\hline Full load current & $13.1[\mathrm{~A}]$ \\
\hline Range of trip settings & $13.1[\mathrm{~A}] \rightarrow 50[\mathrm{~A}]$ \\
\hline Charging time & $1[\mathrm{~ms}]$ \\
\hline Breaking time & $1[\mathrm{~ms}]$ \\
\hline
\end{tabular}

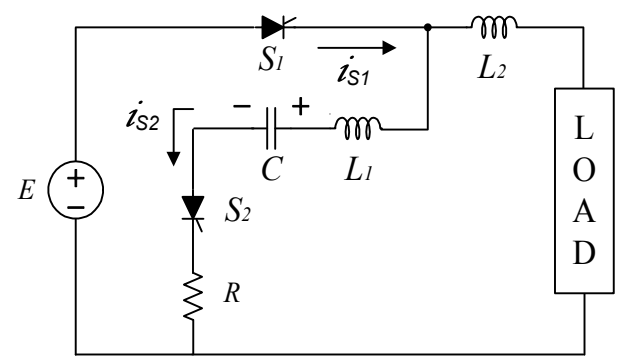

Fig. 6 Equivalent circuit of charging mode

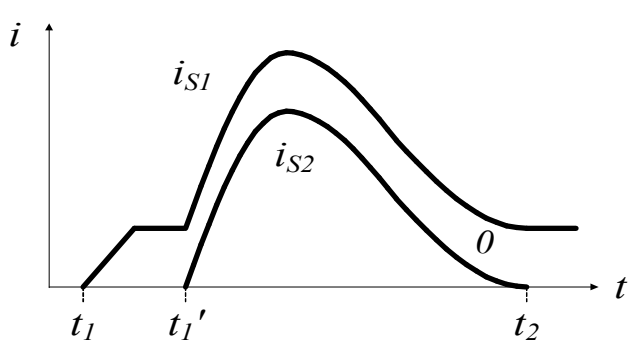

Fig. 7 is1 $_{1}$ and $i_{S 2}$ waveform of charging mode

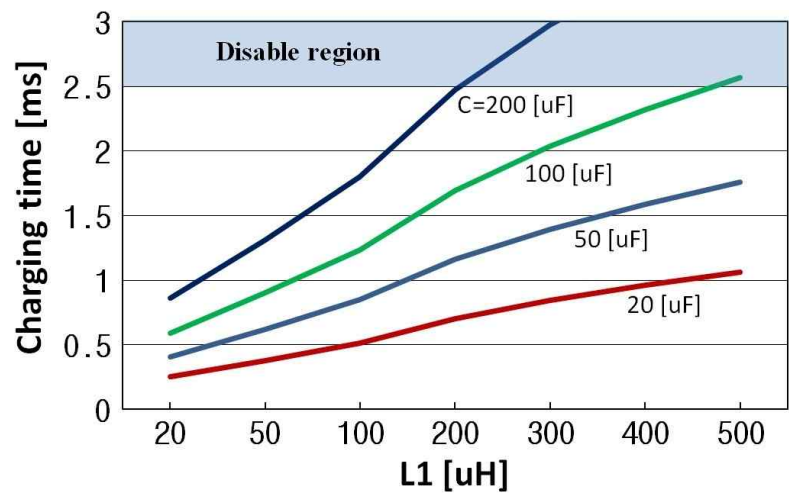

Fig. 8 Charging time of charging current is when $\mathrm{L}_{1}$ and Change

[ms]를 초과하게 되면 충전과 차단 시간이 4 [ms] 이상 소요되어 사용이 불가능하다. 또한 충전 시간이 0.5 [ms] 이하인 경우는 충전 전류 $\mathrm{i}_{\mathrm{S} 2}$ 의 최대값이 커지므로 큰 용량의 소자가 요구된다. 따라서 안정적인 차단을 위 해서는 충전 시간이 $0.5 \sim 1.5[\mathrm{~ms}]$ 의 범위가 되도록 $\mathrm{L}_{1}$ 과 $\mathrm{C}$ 를 설계하는 것이 바람직하다. 그리고 충전 전류는 매우 짧은 시간 동안 흐르므로 저항 $\mathrm{R}$ 은 작은 용량으로 설계가 가능하다. 충전 전류 $\mathrm{i}_{52}$ 는 $\mathrm{DC} \mathrm{SSCB}$ 가 충전 모 드로 동작할 경우에만 흐르며 충전 시간 $\left(\mathrm{t}_{1} \sim \mathrm{t}_{2}\right)$ 이 $0.5 \sim 2$ 
$[\mathrm{ms}]$ 에 불과하므로 저항에는 매우 작은 열이 발생한다. 따라서 저항 $\mathrm{R}$ 은 $5[\mathrm{~W}]$ 의 저항을 사용하여도 무방하다.

\section{B. 차단 모드}

그림 9 는 단락사고 발생 시 $\mathrm{SSCB}$ 의 차단모드 등가회 로이며 그림 10 은 각 소자의 전류 파형이다.

$\mathrm{C}, \mathrm{L}_{1}, \mathrm{~L}_{2}, \mathrm{~S}_{1}, \mathrm{~S}_{3}, \mathrm{D}$ 는 그림 10 에서 보이는 바와 같이 각 소자에 흐르는 전류의 크기를 고려하여 선정해야 한 다. 시간 $\mathrm{t}_{4} \sim \mathrm{t}_{6}$ 까지 흐르는 $\mathrm{L}_{1}-\mathrm{C}$ 공진 전류 $\mathrm{i}_{3} 3$ 는 식 (8) 을 통하여 최대값을 얻을 수 있으므로 그림 8의 충전 시간과 $\mathrm{L}_{1}-\mathrm{C}$ 공진 전류 $\mathrm{i}_{\mathrm{S} 3}$ 의 최대값을 고려하면 $\mathrm{L}_{1}$ 과 $\mathrm{C}$ 를 선정할 수 있다.

그림 11 은 $\mathrm{L}_{1}$ 과 $\mathrm{C}$ 의 용량에 따른 $\mathrm{L}_{1}-\mathrm{C}$ 공진전류 $\mathrm{i}_{\mathrm{S} 3}$ 의 최대값을 나타낸다. $\mathrm{L}_{1}$ 의 용량이 작아지거나 $\mathrm{C}$ 의 용 량이 커질수록 $\mathrm{L}_{1}-\mathrm{C}$ 공진전류 $\mathrm{i}_{\mathrm{S} 3}$ 의 최대값은 증가하게 된다. $\mathrm{L}_{1}-\mathrm{C}$ 공진 전류의 최대값이 크면 큰 용량의 $\mathrm{SCR}$ 과 다이오드를 요구하게 되므로 경제적이지 못하다. 그 러므로 $\mathrm{L}_{1}$ 과 $\mathrm{C}_{\text {는 }} \mathrm{L}_{1}-\mathrm{C}$ 공진 전류 $\mathrm{i}_{\mathrm{S} 3}$ 의 최대값이 200 $[\mathrm{A}]$ 가 넘지 않도록 선정한다. 그리고 단락 전류 $\mathrm{isc}_{\mathrm{Sc}}$ 는 50 $[\mathrm{A}]$ 에서부터 $\mathrm{t}_{4} \sim \mathrm{t}_{6}$ 구간 동안 계속 증가하므로 $\mathrm{L}_{1}-\mathrm{C}$ 공 진 전류 is3는 최대값이 $100[\mathrm{~A}]$ 이상이 되어야 안정적인

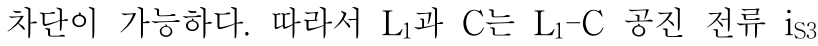
의 최대값이 100 200 [A]의 범위가 되도록 선정해야 한다. 충전 모드의 충전 시간은 $1[\mathrm{~ms}]$ 로 설계하였으므 로 그림 8과 그림 11 을 통하여 두 조건을 만족하는 $\mathrm{L}_{1}$ 과 $\mathrm{C}$ 를 선정하면 $\mathrm{L}_{1}=200[\mathrm{uH}], \mathrm{C}=50[\mathrm{uF}]$ 가 된다.

그림 12 는 $\mathrm{L}_{1}$ 과 $\mathrm{C}$ 의 용량에 따른 커패시터의 최대 전 압을 나타낸다. $\mathrm{L}_{1}$ 과 $\mathrm{C}$ 가 선정이 되면 충전 전류 $\mathrm{i}_{52}$ 는 식 (13)과 식 (14)에 의해 다음과 같이 구해진다.

$$
i_{S 2}=19 \times 10^{5} t e^{-1 \times 10^{4} t}
$$

충전 전류 $\mathrm{i}_{\mathrm{S} 2}$ 의 최대값은 $70[\mathrm{~A}]$ 이며 충전 시간은 약 $1.16[\mathrm{~ms}]$ 가 되므로 충전 모드의 조건에 만족하게 된다. 또한 $\mathrm{L}_{1}-\mathrm{C}$ 공진전류 $\mathrm{i}_{3} 3$ 는 식 (5)를 이용하여 식 (16)을 얻을 수 있다.

$$
i_{S 3}=190 \sin \left(10^{4} \cdot\left(t-t_{4}\right)\right) \quad\left(t_{4} \leq t \leq t_{6}\right)
$$

$\mathrm{L}_{1}-\mathrm{C}$ 공진 전류 $\mathrm{i}_{\mathrm{S} 3}$ 의 주파수는 약 $1.6[\mathrm{kHz}]$ 이며 최 대 전류는 190 [A]가 된다. 이처럼 $\mathrm{L}_{1}-\mathrm{C}$ 공진 전류 $\mathrm{i}_{\mathrm{S} 3}$ 는 부하 전류에 비해 큰 최대값을 갖지만 차단 시간 $\left(\mathrm{t}_{4}\right.$ $\left.\sim \mathrm{t}_{7}\right)$ 이 1 2 [ms]에 불과하므로 매우 짧은 시간 동안만 흐르게 된다. 따라서 $\mathrm{L}_{1}$ 은 자기포화를 고려하여 공극을 크게 설계하면 작은 용량의 크기로 제작이 가능하다.

$\mathrm{S}_{1}$ 이 안정적으로 턴오프 되기 위해서는 단락 전류 isc 의 최대값이 $\mathrm{L}_{1}-\mathrm{C}$ 공진 전류 $\mathrm{i}_{\mathrm{S} 3}$ 의 최대값보다 작아야 한 다. 따라서 $\mathrm{L}_{2}$ 는 식 (17)을 만족하도록 설계하여야 한다.

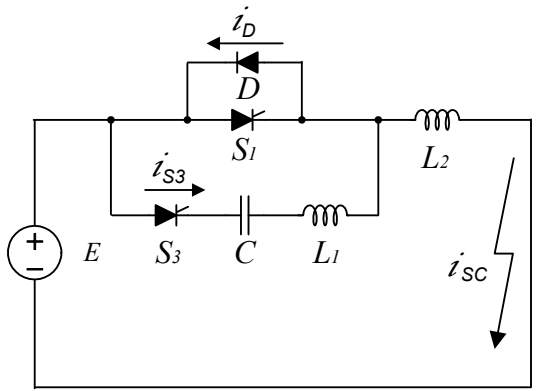

Fig. 9 Equivalent circuit of breaking mode



Fig. $10 i_{S 1}, i_{S 3}, i_{S C}$ and $i_{D}$ waveforms of breaking mode

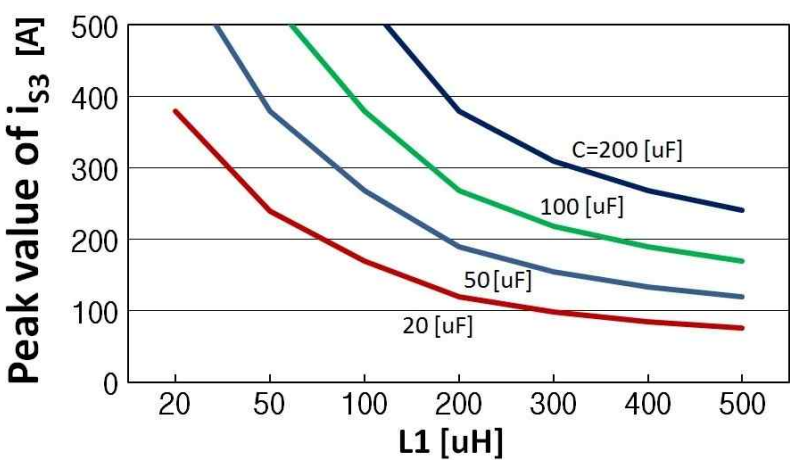

Fig. 11 Peak value of $\mathrm{L}_{1}-\mathrm{C}$ resonant current is 3 when $\mathrm{L}_{1}$ and $\mathrm{C}$ change

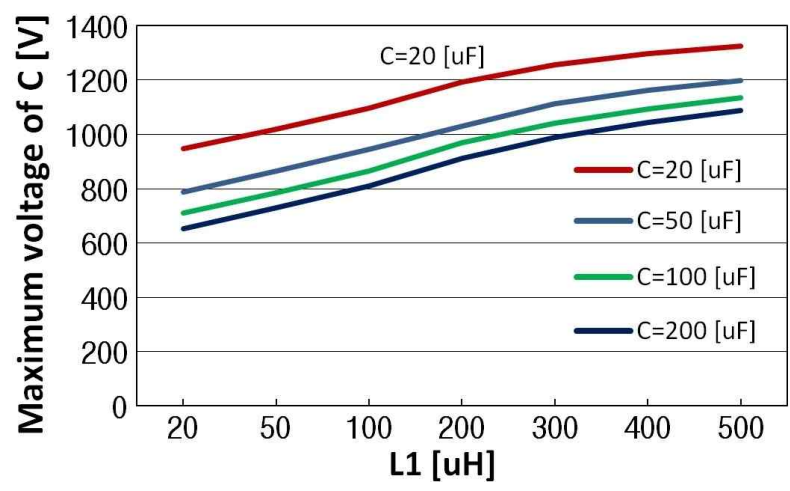

Fig. 12 Maximum voltage of capacitor when $\mathrm{L}_{1}$ and $\mathrm{C}$ change

$$
i_{S C_{\max }}=\frac{E}{L_{2}}\left(t_{6}-t_{3}\right)+i_{L O A D}<i_{S_{\max }}
$$






Fig. 13 Peak value of short-circuit current isc when $\mathrm{L}_{2}$ changes

그림 13 은 $\mathrm{L}_{2}$ 의 용량에 따른 단락 전류 $\mathrm{isc}_{\mathrm{SC}}$ 외대값 과 $\mathrm{L}_{1}-\mathrm{C}$ 공진 전류 $\mathrm{is}_{3}$ 의 최대값을 나타낸다. $\mathrm{L}_{1}=200$ $[\mathrm{uH}], \mathrm{C}=50[\mathrm{uF}]$ 으로 선정되었으므로 $\mathrm{L}_{2}$ 는 $0.6[\mathrm{mH}]$ 이 상으로 설계 한다면 사고 전류의 차단이 가능하다. 하지 만 $\mathrm{L}_{2}$ 가 $0.6 \sim 1[\mathrm{mH}]$ 범위로 설계되는 경우에는 $\mathrm{t}_{5} \sim \mathrm{t}_{6}$ 구 간이 매우 짧으므로 $\mathrm{SCR}$ 의 $\mathrm{t}_{\mathrm{q}}$ 를 확보하지 못하여 차단 이 불안정하게 된다. 따라서 $\mathrm{L}_{2}$ 는 $1 \sim 2[\mathrm{mH}]$ 의 용량으 로 선정하는 것이 바람직하다. 본 연구에서는 안정적인 차단 동작을 위해 $\mathrm{L}_{2}$ 를 $1.5[\mathrm{mH}]$ 로 선정한다.

$\mathrm{L}_{2}$ 의 인덕턴스가 $1.5[\mathrm{mH}]$ 이고 $\mathrm{L}_{2}$ 에 흐르는 전류가 $100[\mathrm{~A}]$ 이상이므로 무게와 부피가 클 것으로 예상이 된 다. 하지만 $\mathrm{L}_{2}$ 의 평균 전류는 전부하 전류의 크기인 13.1 [A]이며 1 2 [ms] 동안만 $110[\mathrm{~A}]$ 의 최대 전류가 흐르 게 되므로 $110[\mathrm{~A}]$ 의 평균전류를 갖는 인덕터에 비해 작은 부피로 제작이 가능하다. $\mathrm{L}_{2}$ 는 평균전류를 고려하 여 제작하되 권선은 $110[\mathrm{~A}]$ 의 순간 전류를 허용할 수 있는 권선의 굵기로 선정하고 코어는 자기포화를 고려 하여 공극을 크게 하면 $\mathrm{L}_{2}$ 는 작은 부피로 제작이 가능 하다. $\mathrm{L}_{2}$ 의 큰 인덕턴스가 단점이 될 수 있으나 $\mathrm{L}_{2}$ 의 인 덕턴스가 작거나 구성되지 않는다면 단락 전류 $\mathrm{isc}_{\mathrm{SS}}$ 매 매 우 커지게 되어 더 큰 $\mathrm{L}_{1}-\mathrm{C}$ 공진 전류와 큰 용량의 $\mathrm{SCR}$, 다이오드가 요구되므로 오히려 시스템의 비용이 상승하게 된다. 따라서 $\mathrm{L}_{2}$ 는 사고 전류를 억제하는 기능 과 $\mathrm{DC} \mathrm{SSCB}$ 의 비용 절감을 위해 필수요소가 된다. $\mathrm{L}_{1}$, $\mathrm{L}_{2}, \mathrm{C}$ 가 선정되었으므로 $\mathrm{SCR}$ 과 다이오드의 선정이 가 능하다. SCR과 다이오드는 약 $10[\mathrm{~ms}]$ 동안 서지 전류 를 허용하므로 $\mathrm{L}_{1}-\mathrm{C}$ 공진 전류 $\mathrm{i}_{\mathrm{S} 3}$ 의 최대값 $190[\mathrm{~A}]$ 를 고려하여 선정하면 된다.

\section{4. 시뮬레이션과 실험 결과}

표 2는 충전모드와 차단모드를 고려하여 선정된 각 소자들의 사양이다.

\section{A. 충전 모드}

그림 14 는 $\mathrm{S}_{1}$ 이 턴온 되면서 나타나는 $\mathrm{S}_{1}$ 의 전압과 전류의 시뮬레이션 파형이다. 그림 15 의 실험 결과 파형 을 통해 ZCS 턴온 동작을 하는 것을 확인 할 수 있다.
Table 2 Experimental model parameters

\begin{tabular}{|c|c|}
\hline Handling Power & $5[\mathrm{~kW}], 380[\mathrm{~V}]$ \\
\hline $\mathrm{L}_{1}$ & $0.2[\mathrm{mH}], \mathrm{i}_{\mathrm{av}}=0[\mathrm{~A}], \mathrm{i}_{\text {peak }}=180[\mathrm{~A}]$ \\
\hline $\mathrm{L}_{2}$ & $1.5[\mathrm{mH}], \mathrm{i}_{\mathrm{av}}=13.1[\mathrm{~A}], \mathrm{i}_{\text {peak }}=110[\mathrm{~A}]$ \\
\hline $\mathrm{C}$ & $50[\mu \mathrm{F}], 1200[\mathrm{VAC}]$ \\
\hline $\mathrm{R}$ & $4[\mathrm{\Omega}], 5[\mathrm{~W}]$ \\
\hline SCR & $1200[\mathrm{~V}], \mathrm{i}_{\mathrm{av}}=50[\mathrm{~A}], \mathrm{i}_{\text {peak }}=1500[\mathrm{~A}]$ \\
\hline Diode & $1200[\mathrm{~V}], \mathrm{i}_{\mathrm{av}}=50[\mathrm{~A}], \mathrm{i}_{\text {peak }}=1500[\mathrm{~A}]$ \\
\hline
\end{tabular}

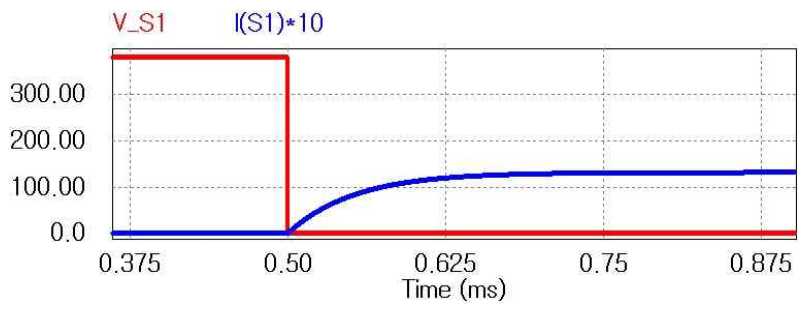

Fig. 14 Voltage $\mathrm{V}_{\mathrm{S} 1}$ and current $\mathrm{i}_{\mathrm{S} 1}$ simulation waveform of switch $\mathrm{S}_{1}$



Fig. 15 Measured voltage $V_{S 1}$ and current is1 waveform of switch $\mathrm{S}_{1}$

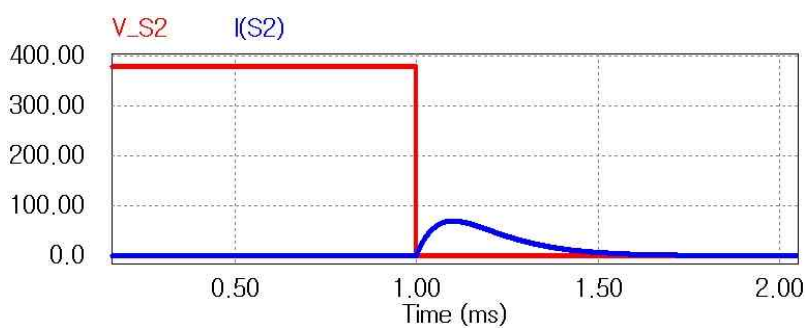


of switch $\mathrm{S}_{2}$

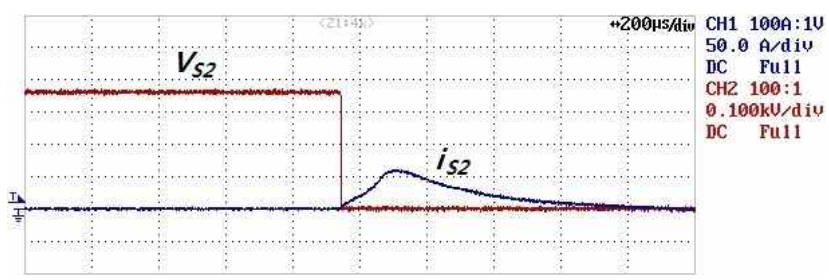


switch $\mathrm{S}_{2}$

그림 16 은 커패시터를 충전하기 위해 $\mathrm{S}_{2}$ 가 턴온 되면 서 나타나는 전압과 전류의 시뮬레이션 파형이다. 그림 17 의 실험 결과 파형을 통해 $\mathrm{S}_{2}$ 는 ZCS 턴온 동작을 하 며 충전 전류가 흐르는 것을 확인 할 수 있다. 


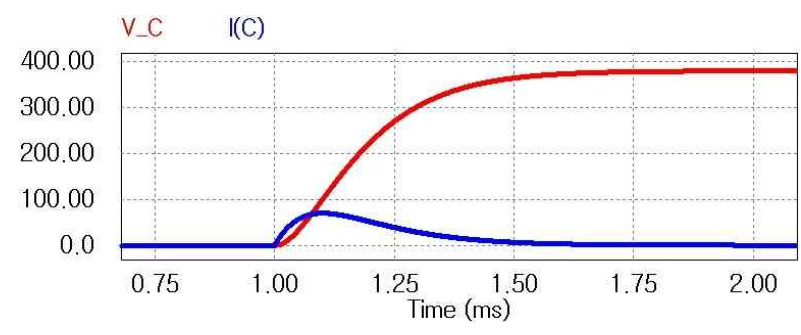

Fig. 18 Voltage $V_{C}$ and current $i_{C}$ simulation waveform of Capacitor

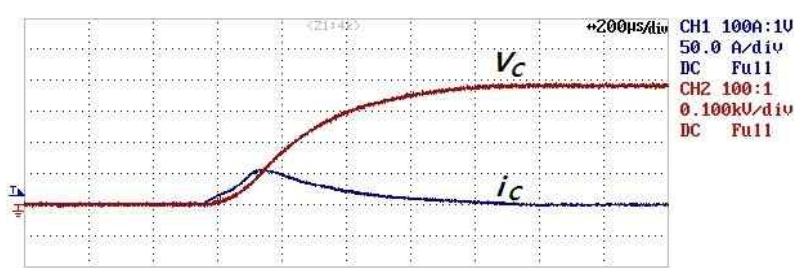

Fig. 19 Measured voltage $\mathrm{V}_{\mathrm{C}}$ and current $\mathrm{i}_{\mathrm{C}}$ waveform of Capacitor

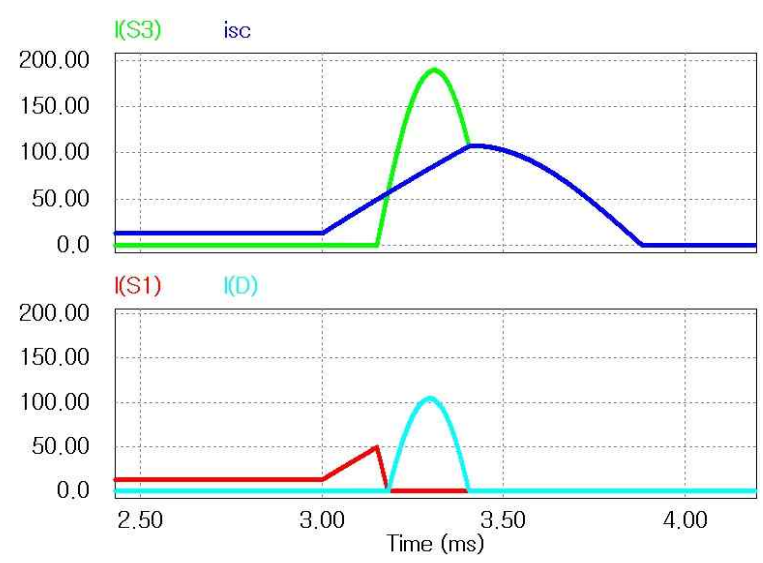

Fig. 20 isc, $_{\mathrm{S} 3}$, is1 and $i_{\mathrm{D}}$ simulation waveform of breaking mode

그림 18 은 커패시터 충전 전압과 충전 전류의 시뮬레 이션 결과 파형이며 그림 19 는 실험 결과 파형이다. $\mathrm{L}_{1}-\mathrm{C}$ 충전 전류는 식 (14)를 만족하며 약 $1.1[\mathrm{~ms}]$ 동안 흐르게 되고 커패시터는 380 [V]로 충전이 된다.

\section{B. 차단 모드}

제안된 $\mathrm{DC} \mathrm{SSCB}$ 의 차단 모드는 단락 사고를 모의하 여 시뮬레이션과 실험을 수행하였다. 사고 전류의 판별 은 전부하 전류의 3 4배를 초과 할 때 이므로 $\mathrm{S}_{1}$ 에 흐 르는 전류가 $50[\mathrm{~A}]$ 를 초과하면 차단 모드가 시작된다.

그림 20 은 단락 사고가 발생 시 $\mathrm{DC} \mathrm{SSCB}$ 의 차단 모 드에서 나타나는 $\mathrm{i}_{\mathrm{SC}}, \mathrm{i}_{\mathrm{S} 3}, \mathrm{i}_{\mathrm{S} 1}, \mathrm{i}_{\mathrm{D}}$ 시뮬레이션 파형이며 그 림 21은 실험 결과 파형이다. $\mathrm{L}_{1}-\mathrm{C}$ 공진 전류 $\mathrm{i}_{\mathrm{S} 3}$ 에 의 해 $\mathrm{S}_{1}$ 이 턴오프 되고 단락 전류 $\mathrm{isc}_{\mathrm{SC}}$ 은 1 [ms]만에 차 단하는 것을 확인 할 수 있다.

그림 22는 $\mathrm{ZCS}$ 턴온 동작을 하는 $\mathrm{S}_{3}$ 의 전압과 전류 시뮬레이션 파형이며 그림 23은 실험 결과 파형이다.



Fig. 21 Measured $i_{S C}, i_{S 3}$, is1 and $i_{D}$ waveform of breaking mode

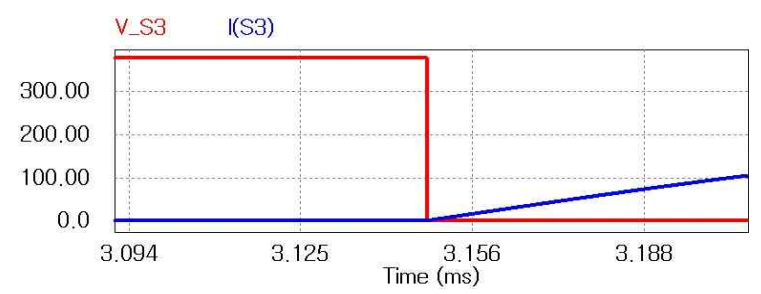

Fig. 22 Voltage $\mathrm{V}_{\mathrm{S} 3}$ and current is simulation waveform of switch $\mathrm{S}_{3}$

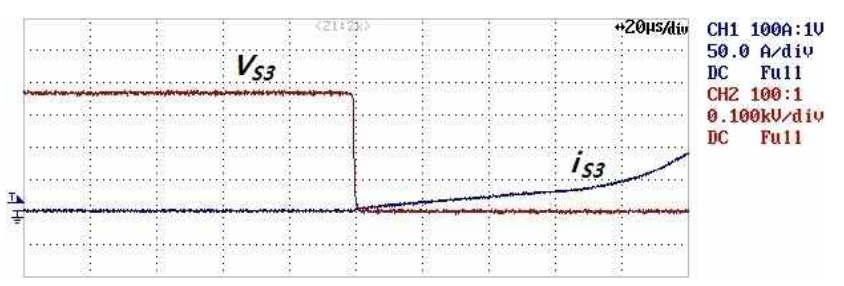

Fig. 23 Measured voltage $\mathrm{V}_{\mathrm{S} 3}$ and current is3 $_{\mathrm{S} 3}$ waveform of switch $\mathrm{S}_{3}$

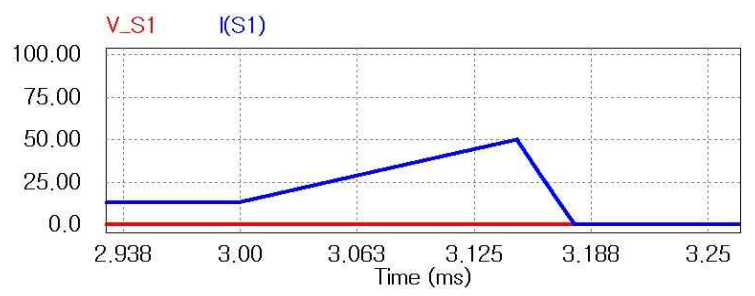

Fig. $24 \mathrm{~V}_{\mathrm{S} 1}$ and $\mathrm{i}_{\mathrm{S} 1}$ turn-off simulation waveform of switch $\mathrm{S}_{1}$



Fig. 25 Measured $V_{S 1}$ and is1 turn-off waveform of switch $\mathrm{S}_{1}$

$\mathrm{ZCS}$ 동작을 하는 $\mathrm{S}_{3}$ 가 턴온 되면서 $\mathrm{L}_{1}-\mathrm{C}$ 공진 전류 가 발생하는 것을 확인 할 수 있다. 
그림 24는 $\mathrm{L}_{1}-\mathrm{C}$ 공진 전류에 의해 $\mathrm{S}_{1}$ 이 ZVS 턴오프 되는 것을 나타내는 시뮬레이션 파형이며 그림 25는 실 험 결과 파형이다. $\mathrm{S}_{1}$ 의 전압이 $0[\mathrm{~V}]$ 를 유지하므로 스 위칭 손실이 발생하지 않는 것을 확인 할 수 있다.

\section{5. 결 론}

분산 전원이 발달함에 따라 $\mathrm{DC}$ 그리드의 높은 전력 품질을 위해서는 $\mathrm{DC} \mathrm{SSCB}$ 는 필수 요소이다. $\mathrm{SCR}$ 은 턴 오프를 하기 위해서 전류 회로가 필요하지만 도통 손실 이 작고 경제적이므로 $\mathrm{DC} \mathrm{SSCB}$ 로 사용하기 적합하다. 하지만 $\mathrm{SCR}$ 을 이용한 기존의 $\mathrm{SSCB}$ 는 $\mathrm{AC}$ 그리드를 기 반으로 제안되었기 때문에 $\mathrm{DC}$ 그리드에 적용하기 힘들 다. 따라서 본 논문에서는 구조가 간단한 새로운 $\mathrm{DC}$ $\mathrm{SSCB}$ 를 제안하였다. 제안한 $\mathrm{DC} \mathrm{SSCB}$ 는 사고 전류를 제한하므로 낮은 사양의 소자 선정이 가능하고 차단에 필요한 보조 $\mathrm{SCR}$ 을 최소화하여 경제성을 확보하였다. 또한 이용되는 모든 $\mathrm{SCR}$ 이 $\mathrm{L}-\mathrm{C}$ 공진을 이용한 $\mathrm{ZVS}$, $\mathrm{ZCS}$ 의 동작을 하므로 스위칭 손실이 매우 작다. 제안한 회로는 단락 사고를 모의하여 시뮬레이션과 실험을 통 해 동작 특성을 검증하였고 다른 $\mathrm{DC}$ 그리드에 적용이 가능하도록 수식을 이용하여 설계 가이드라인을 제시하 였다. 본 논문에서 연구한 $\mathrm{DC} \mathrm{SSCB}$ 는 향후 $\mathrm{DC}$ 그리드 시스템의 설계 및 구현에 활용될 것으로 기대된다.

\section{참 고 문 헌}

[1] D. Boroyevich, et al., "Future electronic power distribution systems a contemplative view," in Proc. IEEE Optimization of Electrical and Electronic Equipment, pp. 1369-1380, 2010.

[2] Chan-Nan Lu and Cheng-Chieh Shen, "Estimation of Sensitive Equipment Disruptions Due to Voltage Sags," IEEE Transactions on power delivery, Vol. 22, No. 2, pp. 1132-1137, April 2007.

[3] Kyung-Ho Lee, "Direct current (DC) power distribution trends and safety measures," The Journal of the Korean Institute of Power Electronics, Vol. 14, No. 2, pp. 21-26, 2009. 4

[4] Dong-Kurl Kwak, "A Electrical Fire Disaster Prevention Device of High Speed and High Precision by using Semiconductor Switching Devices," The Transactions of the Korean Institute of Power Electronics, Vol. 14, No. 5, pp. 423-430, 2009. 10 .

[5] Sung-Min Lee, and Hyo-Sung Kim, "Development of DC Circuit Breaker using Magnet Arc Extinguisher," The Transactions of the Korean Institute of Power Electronics, Vol. 17, No. 1, pp. 21-26, 2012. 2.

[6] Meyer C. and Schroder S, "Design of Solid-state Circuit Breaker for Medium-Voltage Systems," in IEEE PES Transmission \& Distribution Conference, pp. 798-803, 2003.
[7] Christoph Meyer, "Solid-State Circuit Breaker Based on Active Thyristor Topologies," IEEE Trans, Power Electron, Vol. 21, No. 2, pp. 450-458, Mar. 2006

[8] Fang Luo and Jian Chen, "A novel solid state fault current limiter for DC power distribution network," Applied Power Electronics Conference and Exposition. APEC 2008, pp. $1284-1289$.

[9] Mu Jian-guo and Wang Li, "Research on main circuit topology for a novel DC solid-state circuit breaker," Industrial Electronics and Applications (ICIEA), 2010 the 5th IEEE Conference on, pp. 926-930.



김진영 (金珍永)

1977년 7월 30일생. 2004년 부경대 전기공 학과 졸업. 2006년 부산대 대학원 전기공학 과 졸업(석사). 2008년 현재 부경대 대학원 박사과정.

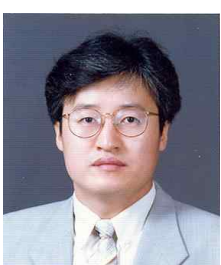

\section{김인동 (金仁東)}

1960년 8월 27일 생. 1984년 서울대 공대 전기공학과 졸업. 1987년 한국과학기술원 전기 및 전자공학과 졸업(석사). 1991년 동 대학원 졸업(공박). 1991년 1996년 대우중 공업 철도차량연구소 책임연구원. 1997년 1998년 미국 Univ. of Tennessee 방문교수. 2004 2005년 미국 Virginia Tech 방문교수. 1996년 현재 부경대 전기공학과 교수.

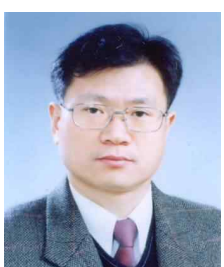

노의철(魯義哲)

1960년 8월 2일생. 1984년 서울대 공대 전 기공학과 졸업. 1986년 한국과학기술원 전 기 및 전자공학과 졸업(석사). 1991년 동 대 학원 졸업(공박). 1997년 1998년 미국 Univ. of Wisconsin-Madison 방문교수. 2005년 2006년 미국 University of California-Irvine 방문교수. 1995년 현 재 부경대 전기공학과 교수. 당 학회 편집위원장. 